\title{
Cervical Cancer Knowledge, Attitude, and Practices: Educational Program Management for Female Workers at Port Said University
}

\author{
Mervat Caber Zagloul ${ }^{1}$, Hanan Elzeblawy Hassan ${ }^{2} \&$ Elsaida Gouda Naser ${ }^{3}$ \\ ${ }^{1}$ Maternity, Obstetric \& Gynecological Nursing, Faculty of Nursing, Port Said University, Egypt \\ ${ }^{2}$ Maternal and Newborn Health Nursing, Faculty of Nursing, Beni-Suef University, Egypt \\ ${ }^{3}$ Maternal and Neonatal Health Nursing, Faculty of Nursing, Fayoum University, Egypt \\ Correspondence: Hanan Elzeblawy Hassan, Maternal and Newborn Health Nursing, Faculty of Nursing, \\ Beni-Suef University, Egypt.
}

Received: March 19, 2020

Accepted: May 9, 2020

Online Published: July 25, 2020

doi:10.20849/ijsn.v5i3.776

URL: https://doi.org/10.20849/ijsn.v5i3.776

\begin{abstract}
Background: Women of all races and ethnicities have the possibility of developing cervical cancer. Cervical cancer has continued to be a significant issue in public health worldwide. Aim: To assess the impact of a cervical cancer educational program on the awareness, attitude, and practice of working women at the University of Port Said. Subject \& Methods; Design: A quasi-experimental design. Setting: The study conducted at Port Said University faculties; Subjects: 260 working women at Port Said University, who accepted to participate in the study. Results: The mean age of the females surveyed was $37.22 \pm 11.00$ years. There has been a general increase in the awareness, practice, and attitude of the studied women about cervical cancer during the different measurement periods compared with before the program; with a highly statistically significant difference at p-values $<0.001$. There was a positive highly statistical significant correlation $(p<0.001)$ between total knowledge and attitude scores as well as total knowledge and practice scores at different times of assessment. Conclusion: The implementation of educational program led to significant improvements in women's knowledge, practices, and attitude. Recommendations: The study can be replicated on a larger sample in different settings. More rigorous researches are required to explore the long-term impact of these programs and to plan an individualized educational system in formulating their educational program.
\end{abstract}

Keywords: cervical cancer, knowledge, attitude, practice

\section{Introduction}

Today, cancer is considered a chronic illness that affects both physical and psychological life. Established based on GLOBOCAN data released by the International Cancer Research Agency; a total of 14.1 million new cases of cancer occurred worldwide and 8.2 million cancer deaths were sustained. It was estimated that in the year 2025 19.3 million new cancer cases would pass. [1] Cancer is the world's largest pathological health issue with broad geographical variability in incidence and has, therefore, become an important item on the health agenda of each country. [2,3] Cancer is a term used for malignant uncontrolled growth of tissues and cells. Cancer starts with irreparable damage to one or more genes that regulate and control cell development, proliferation, and apoptosis in a single cell resulting in further and more genetic damage leading to excessive and abnormal cell proliferation and immune system evasion. [4]

Cervical cancer is the $2^{\text {nd }}$ most common diagnosed cancer and the $3^{\text {rd }}$ leading cause of cancer death from cancer in women under the age of 45 worldwide. [5-8] Estimated 752 women in Egypt diagnosed with cervical cancer in 2014. [9] Annually, 288000 women die of cervical cancer within 2300000 prevalent cases and 510000 incident cases. [6,11,12] Cervical among gynecological cancers worldwide is one of the leading causes of morbidity and mortality. Cervical cancer, in today's world, is mainly a disease prevalent in low-income countries. [13-14] Although, incidence and mortality rates of cervical cancer have fallen significantly in developed countries, in developing countries 83 percent of all new cases occurring annually and 85 percent of all disease deaths occur. [15]

The use of oral contraceptives (OC) is related to increased cervical cancer risk. A recent meta-analysis examined the relationship between the uses of OC, the period of use, and the number of years after use ended. Among 
current $\mathrm{OC}$ users; the risk of cervical cancer increased with length of use (using five years or more versus never being used). The risk decreased until people quit using $\mathrm{OC}$, and the risk returned to that of never users after 10 years or more of cessation. Similar findings have been found in women who are positive for high-risk HPV forms but with greater intervals of confidence due to the limited number of subjects with HPV knowledge. [16] Hormonal contraception has created some risk of dysplasia and thus people who use hormonal contraceptives should be advised to do routine Pap smear screening. [17]

Cancer of the cervix is a preventable disease, and the identification of the premalignant type by cervical screening is a crucial component of its prevention. [11] Screening for cervical cancer is important in reducing cancer mortality. Early diagnosis of cervical cancer has resulted in a reduction in the incidence and mortality associated with invasive cervical cancer of around 40 percent. Awareness, behaviors, and perceptions about the disease in various cultures have been shown to influence women's screening of cervical cancer. Understanding women's awareness and expectations of cervical cancer screening helps to recognize obstacles to early detection, which may help improve screening strategies [18-19]

Informing women about the importance of avoiding cervical cancer, nurses play a vital role. Nursing is a career of great confidence and patients feel comfortable with the knowledge they receive from nurses. Cultural competence is an essential quality that nurses can communicate with their patients in a proper manner. [2, 20, 21]

\subsection{Significance of the Study}

Cervical cancer is the most common malignant tumor in women around the world. It is the most prevalent cancer in women in Egypt, accounting for 18.9 percent of total cases of cancer. [10, 22] Many low and middle-income countries are now facing a double burden of cervical cancer that represents top cancer killers in women over 30 years old. These countries need to adopt joint policies that deal efficiently and effectively with all public health issues. Knowledge raising among the general public about the cervical cancer issue and the prevention mechanisms as well as campaigning for effective policies and services are important strategies for reducing population cervical cancer. [23] Although cervical cancers have severe implications, little is known about Port Said University workers' knowledge of risk factors, causes, screening, and management. We assume that knowledgeable women will be of assistance not only in awareness projects but also in screening campaigns.

\subsection{Aim of the Study}

Evaluate the impact of a cervical cancer educational program on the awareness, attitude, and practice of working women at the University of Port Said.

\subsection{Research Hypotheses}

1) The majority of working females in Port Said University has a lack of knowledge and poor attitude and practices about cervical cancer, before the implementation of the program.

2) After the implementation of the program, working females in Port Said University knowledge, attitude, and practices about cervical cancer will be improved.

\section{Subjects and Methods}

\subsection{Research Design}

A quasi-experimental study design; Pre/Post-interventions were used to fulfill the aim of this study.

\subsection{Setting}

This study was conducted at Port Said University faculties; studied faculties were faculty of Science, Veterinary Medicine, Law, education, Commerce, and Agriculture.

\subsection{Subject}

The studied subjects were selected from the above-mentioned setting. The sample consisted of 260 working female at Port Said University.

\subsubsection{Sample Type}

A purposive sample was utilized to select the study subject.

\subsubsection{Sample Technique}

- $50 \%$ about (6 faculties ) of the total 12 of Port Said University

- Faculties were selected randomly (simple random sample)

- The total number of the working female in the 6 faculties were 260 


\subsection{Subject}

The studied subjects were selected from the above-mentioned sitting (260) working women at Port Said University.

\subsubsection{Inclusion Criteria Include}

- Age from 20 to 60 years

- Not had a history of cervical cancer

- Not under the treatment of chemotherapy or radiotherapy

\subsection{Tools of Data Collection}

Two instruments were used to collect data related to the research variables to attain the objective of the proposed analysis.

\subsubsection{Interviewing Questionnaire Sheet}

Which developed by the researchers based on reviewing related literature, it includes two parts:

\section{A. Part (1):}

- Socio-demographic data such as (residence, age, marital status and educational level).

- Health history of the study subjects which include obstetrics, menstrual and family history.

- Practices of study subjects to early detection measures from cervical cancer such as Pap smear test (through asking questions)

\section{B. Part (2):}

Assessment of the knowledge of working females in Port Said University regarding cervical cancer as (definitions, abnormal signs, and symptoms, risk factors, steps to treat and diagnose cervical cancer early.

\section{Score system}

To obtain the outcome of knowledge, the answers to the questions were classified into 2 or 3 categories according to the type of each question. The answers were graded into 3 categories (2) degree for correct answer (1) degree for an incomplete answer and (0) for an incorrect or unclear answer in the open-ended questions. In the closed-ended questions, the answers were classified into 2 categories (1) degree for a correct answer and (0) for incorrect or don't know. The score of total knowledge was divided into two levels, the female was considered to have a satisfactory level if the score was $60 \%$ or more and unsatisfactory if less than $60 \%$.

\subsubsection{Modified Likert Scale}

A modified Likert scale was used to assess the attitude of working females in Port Said University to cervical cancer. The scale consisted of 18 statements about several issues related to cervical cancer \& early detection measures. The responses were on a three-point Likert scale: "agree", "sometimes", and "disagree."

\section{Score system}

To obtain the outcome of attitude scale, each statement took (2) degree if the response in answering the question was correct, it was considered "a positive attitude", (1) degree if it was "sometimes", and Zero if it was incorrect, it was considered "a negative attitude". The score of total attitude was considered positive if the percent score was greater than $60 \%$, and negative if less.

\subsection{Administrative and Ethical Considerations}

An official letter signed from the dean of Port-Said Faculty of Nursing contains the title and objectives of the study were addressed to the deans of the selected faculties to obtain the official agreement for the research. Before applying the tools (to gain women's. trust and confidence); the study purpose was clarified to each female. That woman's oral consent to participate in the study was obtained. The study was not having any physical, social, or psychological risks on the participant. Data was collected and treated confidentially.

\subsection{Pilot Study}

It was conducted on $10 \%$ of the total sample it was 26 female and which excluded from the sample size. Feedback of pilot study was done; the language of the questionnaires was modified to be easily understood by the participants. 


\subsection{Tools Validity}

It was tested for content validity by a jury of five experts in the field of obstetric and maternity nursing to ascertain relevance and completeness.

\subsection{Tools Reliability}

Cronbach's alpha coefficient of 0.78 was calculated to assess the reliability of the developed tool through their internal consistency.

\subsection{Educational Program}

The Educational program was carried out through the following phases.

\section{Phase I: (Preparatory Phase)}

After a comprehensive review of the literature, the assessment tools for data collection were developed to determine the females' needs.

\section{Phase II: (The Planning Phase)}

The cervical cancer program was designed based on the baseline data collected from a pre-program assessment using the self-administrated questionnaire, and Likert scale as well as literature review, which aimed to improve the studied female's deficit knowledge, attitude, and practice regarding cervical cancer. A booklet was prepared in a simple Arabic language and a clear, concise manner. The booklet included definition of cervical cancer, determine the prevalence of cervical cancer, mention risk factors, enumerate abnormal signs and symptoms, discuss the importance of early detection measures from cervical cancer, list types of treatment and identify preventive measures from cervical cancer. Constructing the utilized program contents was based on the level of educations and needs, selecting suitable teaching methods and the appropriate media. Teaching methods included lecture, discussion, demonstration and the media include a booklet and role-play. The booklet was given to the studied females by the researcher at the end of the educational program.

\section{Program implementation:}

The study started from the beginning of July 2019 to the end of February 2020. A pretest was done for (260 female) who working at Port Said University. The pretest was done at the beginning of July 2019. The preparation of the program took 8 weeks. The program implementation started from the beginning of September to the end of October 2019. After 3 months (as a follow-up of the program), and 4 weeks for a follow-up test post-test was performed. Implementation of the program was carried out at the previously mentioned settings. The subject material used has been sequenced via the four sessions. The length of each session varied from 30 to 45 minutes including discussion times based on females' achievement, progress, and feedback of the females. Sessions started according to women's suitable time, usually at $10 \mathrm{Am}$. Females were divided into small groups, each group includes about 15 to 17 females (depends on female's circumstances) in each session and the content was implemented for each group at every session separately for 2 weeks (3 days/week).

\section{Program evaluation:}

After the implementation of the program, the post-test was carried out on the studied female knowledge, attitude, and practice using the same pre-test format to determine the effectiveness of the implemented program; this was done immediately after the intervention and after three months of program implementation. The test was completed in about 30 minutes.

\subsection{Administrative Design}

An official letter signed from the dean of Port-Said Faculty of Nursing contains the title and objectives of the study were directed to the deans of the selected faculties to obtain the official agreement to conduct the study.

\subsection{Statistical Design}

The data collected were checked before computerized entry; statistical analysis was performed via SPSS Version 11. Data were presented in the table by using Mean, Standard deviation, Number, Percentage distribution, Correlation Coefficient (r) and Paired T-test. Column and Pie chart used for graphic presentation.

\section{Results}

Table 1 shows the women's socio-demographic data; the mean age of them was $37.22 \pm 11.00$ years, and $60.0 \%$ of women live in rural areas. Regarding educational level, $52.3 \%$ of them had middle education, and regarding marital status, $(82.7 \%)$ of them was married.

Table 2 indicates that only $3.5 \%$ of the studied women had a family history of cervical cancer, $(77.8 \%)$ of them 
had first-degree relation (mother). Regarding the studied women age at menarche, the mean age was $13.09 \pm 1.32$ years.

Table 3 shows women's obstetric history. It showed that $71.3 \%$ of them had $1-3$ times of delivery and only $5.0 \%$ of them had more than three times of abortion. The mean age of the women at first birth were $22.06 \pm 2.91$ years. Regarding the history of breastfeeding, the majority of the studied women $(91.7 \%)$ mentioned that breastfeed their babies.

Table 4 displays practices of Pap smear test among studied women. The majority of them (96.2 \%) were not doing this test before. Regarding the obstacles that prevent them from doing Pap smear test, more than one third $(35.2 \%)$ of them did not know where is the test performed as reported from the women.

Figure 1 portrays women's source of knowledge about cervical cancer. It illustrated that the most common source of knowledge about cervical cancer was mass media (50.0\%), followed by physicians $(27.0 \%)$, only $15.0 \%$ took their information from books.

Table 5 shows a general improvement in all items of knowledge of the studied women regarding cervical cancer during the different assessment periods as compared to before the program. However, a slight mean decline occurred after three months of program implementation with a highly statistically significant difference observed between three times of assessments at p-values $(<0.001)$. Regarding knowledge of the studied women about Pap smear test and prevention of cervical cancer; the results revealed that there was highly statistically significant difference in relation to items of Pap smear and prevention of cervical cancer at three times of assessments $(\mathrm{P}<$ 0.001). Moreover, the same table shows a highly statistically significant difference before the program, immediately post-program and after three months of program implementation in relation to all items of knowledge about treatment of cancer $(\mathrm{P}<0.001)$.

Figure 2 portrays the studied women practices of Pap smear test before and 3-months after of program implementation. It is clear the improvement of women practices regarding Pap smear; 3-months after program $88.8 \%$ of the studied sample performed the test compared to only $8.1 \%$ before program.

Table 6 indicates that; there was a highly statistically significant difference $(\mathrm{p}<0.001)$ at different times of assessment in relation to attitude of the studied women about cervical cancer and early detection measures.

Table 7 presents a positive highly statistically significant correlation between women's total knowledge scores and their total practice, and attitude scores, as well, in both immediate implementation and 3-months later program implementation.

Table 8 shows that there was a positive highly statistically significant correlation between women's total knowledge scores and their educational level and total practice scores and educational level immediately implementation. On the other hand, there was a statistically significant negative association between total practice scores and age prior to the introduction of the program.

Table 1. Studied women's socio-demographic characteristics

\begin{tabular}{lll}
\hline Items & Number (260) & \% (100) \\
\hline Age & & 32 \\
\hline$-20-30$ years & 48 & $18.5 \%$ \\
\hline$-31-40$ years & 83 & $31.9 \%$ \\
\hline$-41-50$ years & 37 & $14.2 \%$ \\
\hline$-51-60$ years & $37.22 \pm 11.00$ & \\
\hline Mean \pm SD & & $40.0 \%$ \\
\hline Residence & 104 & $60.0 \%$ \\
\hline - Urban & 156 & \\
\hline - Rural & & $7.7 \%$ \\
\hline Marital Status & 20 & $82.7 \%$ \\
\hline - Single & 215 & \\
\hline - Married & & \\
\hline
\end{tabular}




\begin{tabular}{lll}
\hline - Widowed & 21 & $8.1 \%$ \\
\hline - Divorced & 4 & $1.5 \% \%$ \\
\hline Level of Education & & \\
\hline -High education & 80 & $30.8 \%$ \\
\hline -Above middle education & 44 & $16.9 \%$ \\
\hline -Middle education & 136 & $52.3 \%$ \\
\hline
\end{tabular}

Table 2. Family \& menstrual history of the studied women

\begin{tabular}{lll}
\hline Items & Number $\mathbf{( 2 6 0 )}$ & $\mathbf{\% ( 1 0 0 )}$ \\
\hline Family history of cervical cancer & & \\
\hline Yes & 9 & 3.5 \\
\hline No & 251 & 96.5 \\
\hline Relation to women $(\mathbf{N}=\mathbf{9})$ & & 77.8 \\
\hline Mother & 7 & 22.2 \\
\hline Sister & 2 & \\
\hline Age at menarche & & 7.7 \\
\hline $9-11$ years & 20 & 81.9 \\
\hline $12-15$ years & 213 & 10.4 \\
\hline above 16 years & 27 & $13.09 \pm 1.32$ years \\
\hline Mean \pm SD & &
\end{tabular}

Table 3. Obstetrical history of the studied women

\begin{tabular}{lcc}
\hline Items & Number (240) & \% (100) \\
\hline Number of deliveries & 171 & 71.3 \\
\hline $1-3$ & 65 & 27.1 \\
\hline $4-6$ & 4 & 1.7 \\
\hline 7 and above & 123 & 51.25 \\
\hline Number of abortions & 81 & 33.8 \\
\hline None & 24 & 10.0 \\
\hline One & 12 & 5.0 \\
\hline Two & & 37.1 \\
\hline Three and above & 89 & 61.3 \\
\hline Age at first birth & 147 & 1.7 \\
\hline $15-20$ years & 4 & \\
\hline $21-30$ years & $22.06 \pm 2.91$ & \\
\hline 30 years and over & & 81.7 \\
\hline Mean \pm SD & 220 & \\
\hline Breastfeeding & 20 & \\
\hline Yes & & \\
\hline No & & \\
\hline Menopause & & \\
\hline
\end{tabular}




\begin{tabular}{lcc}
\hline Yes & 64 & 26.7 \\
\hline No & 176 & 73.3 \\
\hline Age at menopause $(\mathbf{N}=\mathbf{6 4})$ & & \\
\hline $40-45$ years & 16 & 25.0 \\
\hline $46-50$ years & 40 & 62.5 \\
\hline 51 years and over & 8 & 12.5 \\
\hline Total & 64 & 100 \\
\hline Mean \pm SD & $47.62 \pm 2.46$ & \\
\hline
\end{tabular}

Table 4. Practices of pap smear test for the studied women before the program

\begin{tabular}{lll}
\hline Items & Number & $\mathbf{\%}$ \\
\hline Doing Pap Smears Test & 10 & 3.8 \\
\hline Yes & 250 & 96.2 \\
\hline No & & \\
\hline The date of last Pap test $(\mathbf{N}=\mathbf{1 0})$ & 2 & 20.0 \\
\hline A year ago & 2 & 20.0 \\
\hline Two years ago & 6 & 60.0 \\
\hline More than 5 years ago & & \\
\hline The obstacles for doing Pap Smears $(\mathbf{N}=\mathbf{2 5 0})$ & 66 & 26.4 \\
\hline Embarrassment & 56 & 22.4 \\
\hline Fear from positive result & 24 & 9.6 \\
\hline Cost & 88 & 35.2 \\
\hline Not know where is the test performed & 16 & 6.4 \\
\hline Not have any problems &
\end{tabular}

Distribution of the Studied Women Regarding their Knowledge Source about Cervical Cancer
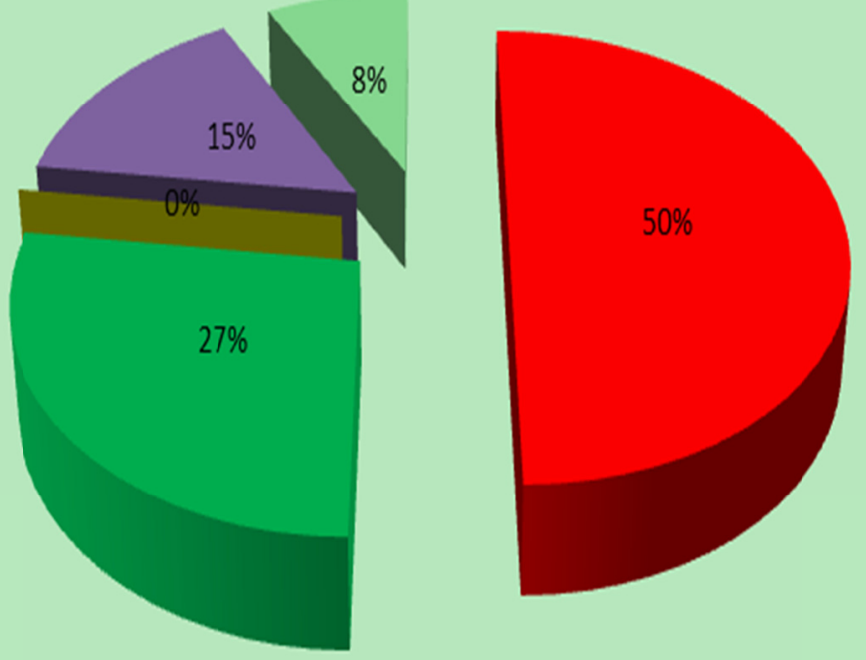

- Mass Media

I physicians

Nurses

$\square$ Relatives

Books

Figure 1. Women's source of knowledge regarding cervical cancer 
Table 5. Women's mean knowledge scores for cervical cancer, its prevention and treatment

\begin{tabular}{|c|c|c|c|c|c|c|c|}
\hline \multirow[b]{2}{*}{ Items } & \multirow{2}{*}{$\begin{array}{l}\text { Pre-program } \\
\text { Mean } \pm \text { SD }\end{array}$} & \multicolumn{3}{|c|}{ Immediately after program } & \multicolumn{3}{|c|}{ 3-months after program } \\
\hline & & Mean \pm SD & $\begin{array}{l}\text { Paired } \\
\text { (t1) }\end{array}$ & $\begin{array}{l}(P) \\
\text { value }\end{array}$ & Mean \pm SD & $\begin{array}{l}\text { Paired } \\
\text { (t1) }\end{array}$ & $\begin{array}{l}\text { (P) } \\
\text { value }\end{array}$ \\
\hline \multicolumn{8}{|c|}{ Women's Knowledge Scores for Cervical Cancer } \\
\hline Definition of cervical cancer & $0.44 \pm 0.49$ & $1.47 \pm 0.55$ & 29.64 & $<0.001$ & $0.66 \pm 0.66$ & 8.80 & $<0.001$ \\
\hline $\begin{array}{l}\text { Dangerous risk factor of cervical } \\
\text { cancer }\end{array}$ & $0.07 \pm 0.26$ & $0.86 \pm 0.34$ & 30.71 & $<0.001$ & $0.73 \pm 0.44$ & 6.29 & $<0.001$ \\
\hline Group at risk of cervical cancer & $0.35 \pm 0.51$ & $1.75 \pm 0.49$ & 35.90 & $<0.001$ & $1.54 \pm 0.63$ & 7.65 & $<0.001$ \\
\hline The symptoms of cervical cancer & $0.51 \pm 0.53$ & $1.71 \pm 0.48$ & 31.52 & $<0.001$ & $1.5 \pm 0.58$ & 0.33 & $<0.001$ \\
\hline \multicolumn{8}{|c|}{ Knowledge Scores of the Studied Women Regarding Pap smear and prevention of Cervical Cancer } \\
\hline Definition of Pap smear & $0.33 \pm 0.50$ & $1.33 \pm 0.59$ & 27.92 & $<0.001$ & $1.15 \pm 0.63$ & 6.97 & $<0.001$ \\
\hline $\begin{array}{l}\text { Stage of life women should do Pap } \\
\text { smear }\end{array}$ & $0.06=$ & 0.8 & 35.65 & $<0.001$ & $0.76 \pm 0.42$ & 6.02 & $<0.001$ \\
\hline Proper frequency of Pap smear & $0.12 \pm$ & $0.84 \pm$ & 26.00 & $<0$. & $0.67 \pm 0.46$ & 7.26 & $<0.001$ \\
\hline $\begin{array}{l}\text { Preventive methods of cervical } \\
\text { cancer }\end{array}$ & $0.20 \pm 0.40$ & $1.60 \pm 0.52$ & 35.90 & $<0.001$ & $1.38 \pm 0.60$ & 7.75 & $<0.001$ \\
\hline Vaccination against cervical cancer & $0.61 \pm 0.24$ & $0.95 \pm 0.21$ & 46.32 & $<0.001$ & $0.80 \pm 0.39$ & 6.76 & $<0.001$ \\
\hline \multicolumn{8}{|c|}{ Women's Knowledge Scores for Treatment of Cancer } \\
\hline The ways to treat cancer & $0.78 \pm 0.48$ & $1.81 \pm 0.42$ & 31.57 & $<0.001$ & $1.56 \pm 0.58$ & 8.51 & $<0.001$ \\
\hline The purpose of chemotherapy & $0.87 \pm 0.51$ & $1.80 \pm 0.40$ & 27.75 & $<0.001$ & $1.58 \pm 0.55$ & 8.33 & $<0.001$ \\
\hline The ways to give chemotherapy & $0.45 \pm 0.53$ & $1.53 \pm 0.52$ & 29.64 & $<0.001$ & $1.38 \pm 0.51$ & 6.76 & $<0.001$ \\
\hline
\end{tabular}

A statistical significant difference $(\mathrm{P} \leq 0.05)$

A highly statistical significant difference $(\mathrm{P} \leq 0.001)$

Paired $\left(\tau_{1}\right)$ : Before program and immediately after

Paired $\left(\tau_{2}\right)$ : immediately after and after 3 months

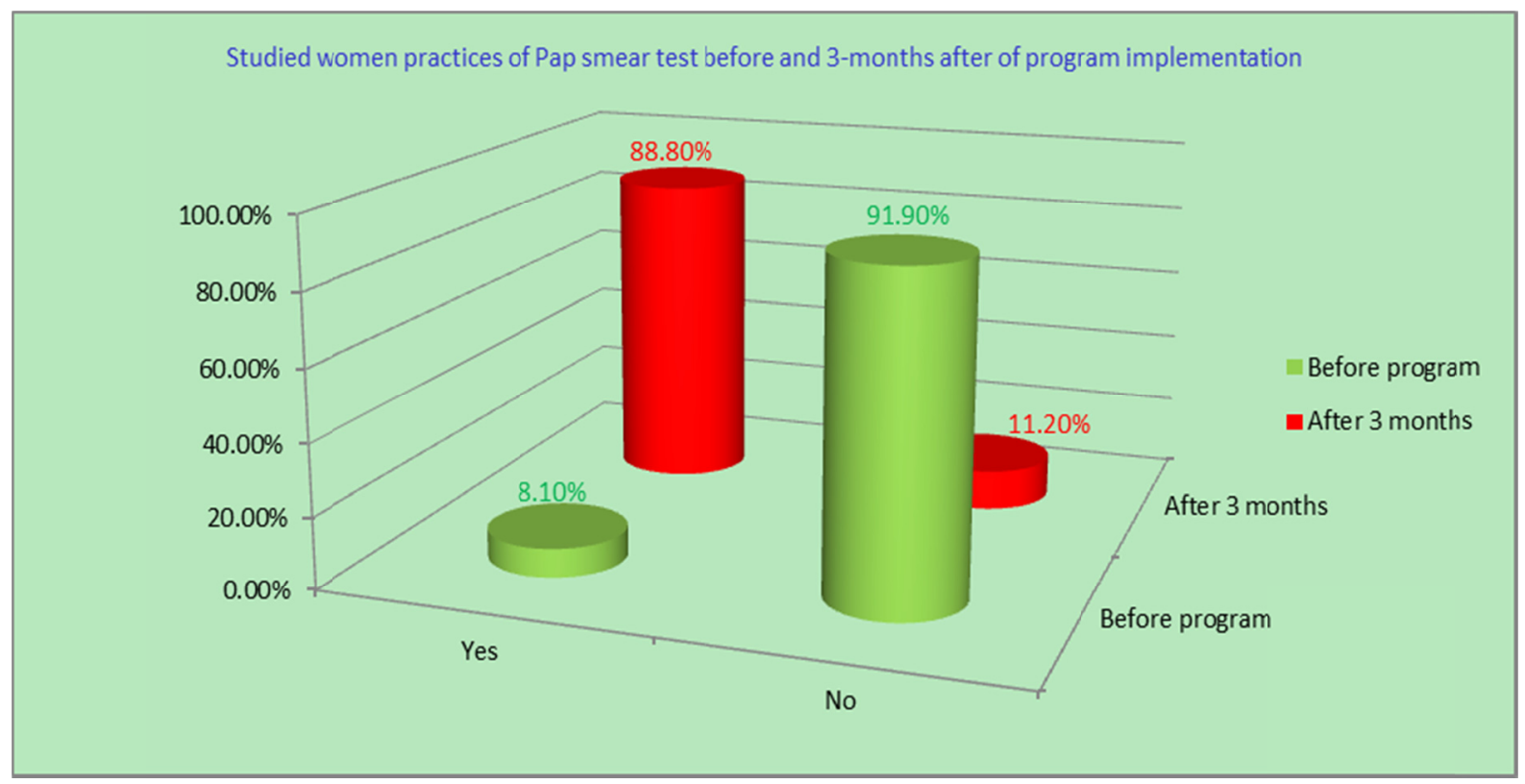

Figure 2. Studied women practices of Pap smear test before and 3-months after of program implementation 
Table 6. Mean attitude scores of the studied women regarding cervical cancer

\begin{tabular}{|c|c|c|c|c|c|c|c|c|}
\hline \multirow{3}{*}{ Items } & \multirow{3}{*}{$\begin{array}{l}\text { Total } \\
\text { score }\end{array}$} & \multirow{3}{*}{$\begin{array}{l}\text { Pre-program } \\
\text { Mean } \pm \text { SD }\end{array}$} & \multicolumn{3}{|c|}{ Immediately after program } & \multicolumn{3}{|c|}{ 3-months after program } \\
\hline & & & \multirow{2}{*}{ Mean \pm SD } & \multicolumn{2}{|c|}{ Paired (P) } & \multirow{2}{*}{ Mean \pm SD } & \multirow{2}{*}{$\begin{array}{l}\text { Paired } \\
\text { (t1) }\end{array}$} & \multirow{2}{*}{$\begin{array}{l}(P) \\
\text { value }\end{array}$} \\
\hline & & & & (t1) & value & & & \\
\hline Cervical Cancer & 6 & $2.11 \pm 1.40$ & $3.77 \pm 1.36$ & 20.73 & $<0.001$ & $3.78 \pm 1.28$ & 0.13 & $<0.001$ \\
\hline Early Detection Measures & 14 & $8.10 \pm 2.72$ & $11.66 \pm 1.78$ & 22.51 & $<0.001$ & $11.51 \pm 1.76$ & 6.27 & $<0.001$ \\
\hline Total Attitude & 36 & $18.00 \pm 5.27$ & $28.00 \pm 3.46$ & 28.84 & $<0.001$ & $27.76 \pm 3.58$ & 4.26 & $<0.001$ \\
\hline
\end{tabular}

A statistical significant difference $(\mathrm{P} \leq 0.05)$

A highly statistical significant difference $(\mathrm{P} \leq 0.001)$

Paired $\left(\tau_{1}\right)$ : Before program and immediately after

Paired $\left(\tau_{2}\right)$ : immediately after and after 3 months

Table 7. Correlation coefficient between women's total knowledge score and attitude \& practice scores regarding cervical cancer

\begin{tabular}{lllllll}
\hline \multirow{2}{*}{ Variables } & \multicolumn{7}{c}{ Total Knowledge } \\
\cline { 2 - 7 } & \multicolumn{2}{c}{ Pre-program } & \multicolumn{2}{l}{ Immediately after } & \multicolumn{2}{c}{ After three months } \\
\cline { 2 - 7 } & $\mathbf{r}$ & $\mathbf{p}$ & $\mathbf{r}$ & $\mathbf{p}$ & $\mathbf{r}$ & $\mathbf{P}$ \\
\hline Attitude & 0.138 & $<0.005$ & 0.455 & $<0.001$ & 0.725 & $<0.001$ \\
\hline Practice & - & - & 0.373 & $<0.001$ & 0.288 & $<0.001$ \\
\hline
\end{tabular}

A statistical significant difference $(\mathrm{P} \leq 0.05)$

A highly statistical significant difference $(\mathrm{P} \leq 0.001)$

Table 8. Correlation coefficient between women's total knowledge, attitude, and practice scores regarding cervical cancer and demographic characteristics of the studied women

\begin{tabular}{llllll}
\hline \multirow{2}{*}{ Variables } & & \multicolumn{2}{c}{ Age } & \multicolumn{2}{c}{ Level of Education } \\
\cline { 3 - 6 } Knowledge & Pre-program & 0.122 & $\mathbf{p}$ & $\mathbf{r}$ & $\mathbf{p}$ \\
\cline { 2 - 6 } & Immediately after & -0.135 & $<0.005$ & 0.121 & $>0.005$ \\
\cline { 2 - 6 } & After three months & 0.895 & $>0.005$ & 0.288 & $<0.001$ \\
\hline \multirow{3}{*}{ Attitude } & Pre-program & -0.142 & $<0.005$ & 0.143 & $<0.005$ \\
\cline { 2 - 6 } & Immediately after & 0.083 & $>0.005$ & 0.117 & $>0.005$ \\
\hline \multirow{3}{*}{ Practice } & After three months & -0.045 & $>0.005$ & -0.116 & $>0.005$ \\
\cline { 2 - 6 } & Pre-program & - & - & - & - \\
\cline { 2 - 6 } & Immediately after & -0.107 & $>0.005$ & 0.213 & $<0.001$ \\
\cline { 2 - 6 } & After three months & -0.039 & $>0.005$ & 0.119 & $>0.005$ \\
\hline
\end{tabular}

A statistical significant difference $(\mathrm{P} \leq 0.05)$

A highly statistical significant difference $(\mathrm{P} \leq 0.001)$

\section{Discussion}

While being preventable by early detection, cervical cancer is regarded as an acute public health issue and one of the main causes of increased mortality/mortality among women. Therefore, Healthy People 2020 has outlined a central delineated aim of reducing the reported new cases. However, with the wave of lack of female knowledge and understanding of nature, risk factors, causes, diagnosis, and interpretation of their preventive measures and 
the technique of detection screening measures; this aim is hard to achieve. [4, 24, 25]

Cervical cancer treatment by all activities and programs aimed at reducing the burden of cancer in a population either through reducing cancer incidence or mortality rate or by reducing cancer suffering. Prevention, early detection, diagnosis, treatment, psychosocial support, and palliative care are components of cancer prevention which can reduce cancer burdens. [26]

Screening for cervical cancer is critical in reducing cancer mortality. The 5-year survival rate is over 95 percent when cancer is diagnosed early. As for cervical cancer, early diagnosis has resulted in the incidence and mortality associated with invasive cervical cancer declining by nearly 40 percent. [18]

As regards women's characteristics, the results of present study revealed that women's mean age was $37.22 \pm$ 11.00 years. It was clear that $(60.0 \%)$ of them were living in rural areas, and regarding marital status, more than three-quarters $(82.7 \%)$ of them were married. Added to this is $52.3 \%$ of women had middle education. In fact, the factors of educational level would certainly have an impact on the knowledge, attitude, and practices of these women regarding cervical cancer. This finding is in accordance with, Arshad et al., (2010) who has stated that; consideration of women's educational status is an important factor in planning educational programs to improve knowledge on cervical cancer screening and prevention. [27]

Hajian-Tilaki andKaveh-Ahangar (2010) have stated that late age at the $1^{\text {st }}$ birth and abortion were the most important reproductive factors associated with cancer risk; Consequently, the author proposed early cervical cancer screening tests for women with such risk factors. [28] Moreover, Torres-Mejía andAngeles-Llerenas (2009) documented that early age at menarche, late age at first pregnancy, and late age at menopause have been associated with an increased risk of cancer. [29] As the results of the current study revealed that over $12.5 \%$, above 40 years, $7.7 \%$ of the studied women reported early age of menarche, $37.1 \%$ of them had early age at first birth (15 - 20 years), $26.7 \%$ were menopause and $46.1 \%$ of them their age at menopause was 51 years. Hence, it was very important to implement an educational program for these women to minimize the risk of incidence for them.

According to the educational program about cervical cancer to improve women's knowledge, attitude, and practice, it was mandatory to assess their baseline knowledge, attitude and practice. The results of the present study revealed that the mean scores of women' knowledge before the program implementation were generally deficient. This may be due to absent of designed educational program which provided to women. The results of the present study revealed that the mean scores of women's knowledge before the program implementation were generally deficient. This may be due to the absence of a designed educational program provided to women. The results of the present study revealed that the mean scores of women's knowledge were significantly improved in all areas of knowledge regarding cervical cancer $(p<0.001)$ after program implementation. It could be due to the entire participant women were interested to get more information about this topic. Such findings were in line with the research of Taha et al., (2010), who studied the educational intervention to enhance cervical health awareness among women in Jordan, finding that the mean score of cervical cancer awareness increased significantly from 10.9 in the pre-test to 13.5 in the post-test $(\mathrm{P}<0.001)$. [30] Furthermore, Rao et al., (2005, who researched the acceptability and efficacy of a rural women's health awareness program in India, reported that a substantial increase in the overall understanding of cervical cancer $(\mathrm{P}<0.001)$ following the educational intervention and claimed that a community-oriented educational intervention program emphasizing the right technique would result in the desired behavioral change among women. [31]

Along the same side, the study by Abd El Aziz et al., (2009) who analyzed the effect of a health education intervention program along with cervical cancer among women in a Semi-urban area in Alexandria, Egypt, found that there was a substantial increase in all of the intervention group's awareness from pre- to post-test. [32] In addition, Karayurt et al., (2008) emphasized that healthcare professionals are able to build successful healthcare systems and enable young people to learn healthy awareness and health behaviors. [33] Banning, (2010), also, reported that black British women need health education focusing on cancer and its related risk factors, cancer screening technique screening recommendations. [34]

The results of the present study revealed that the mean scores of women' knowledge before the program the implementation was deficient about cervical cancer but there was a significant improvement immediately post-program and after three months of program implementation. This result could be due to the effectiveness of the program and the readiness of the working women to gain more information. This result was supported by Gupta, (2009) reported that women's awareness and practices for early detection cervical examination were found to be insufficient in respondents, but substantial changes were observed following the intervention. [35]

The results of the present study revealed that a general improvement in all items of knowledge of the studied 
women regarding cervical cancer during the different assessment periods as compared to before the program at $\mathrm{p}$-values $<0.001$. This could be attributed to the ability of the women to gaining knowledge easily. This finding was in the agreement with Ali et al., (2010) who have highlighted that the majority of the study subjects are not adequately equipped with knowledge concerning cervical cancer and emphasized continuing medical education programs should be started at their workplaces to spread knowledge about this disease. [13]

Furthermore, Wright et al., (2010) reported that the degree of information on cervical cancer was small at baseline; only around $15.0 \%$ and $6.9 \%$ of participants in the intervention and control groups, respectively, had heard of cervical cancer while substantial increases in proportions were observed in the intervention group on the understanding of cervical cancer (61.7\%), associated symptoms and risk factors such as early sexual appearance, smoking, and promiscuity. [36] Al Sairafia \& Mohamed (2009) also stated that a well-designed cervical cancer education program and screening benefits would increase awareness among Kuwaiti women. [37]

The results of the present study revealed that the mean scores of women' knowledge before the program implementation was deficient about Pap smear test and prevention of cervical cancer. This is in agreement with Hoque,(2010), who studied cervical cancer awareness and preventive behavior among female university students in South Africa and reported that just $31 \%$ of participants had heard of the Pap smear test and one third (33\%) of them knew that Pap smear was used for cervical cancer detection. [38] Also, Head et al., (2009) also found that few participants grasped the definition and the significance of the word "Pap smear" in their study of Pap smear awareness among young women after the introduction of the HPV vaccine; there appears to be no increase in women's knowledge following development of the HPV vaccine and added that poor knowledge of Pap smear may affect young women's understanding of their overall sexual health. [39]

However, Tan et al., (2010) reported that the level of knowledge of respondents on cervical cancer and its prevention wasn't sufficient, and recommended that more educational campaigns should be implemented in university campuses to provide knowledge of the prevention of cervical cancer to working women. [40] Meanwhile, Ilter et al., (2010) found that cervical screening awareness was high (70\%), and (51\%) of the subjects were at least once had a Pap smear test. [41]

The current study showed a significant improvement in women's knowledge regarding Pap smear test and prevention of cervical cancer immediately posttest and after three months of program implementation. This might be accounted for women's interest to learn and acquire knowledge in these topics. This result was supported by Peters et al., (2010) who reported that educational programs based on the importance of cervical screening can have a positive effect on early patient detection and diagnosis at the early stages of the disease.[42]

On the same line $O^{\prime}$ Brien et al., (2010) reported that the randomized study of an educational intervention showed improved Pap screening rates, as well as increased awareness of cervical cancer and Pap test. [43] Furthermore, Papa et al., 2009) who researched the evaluation of the role of education in women's understanding and acceptance of adjunct high-risk human Papillomavirus testing for cervical cancer screening found that, understanding concerning HPV and cervical cancer screening had been improved statistically after the intervention. [44] Also, Allahverdipour \& Emami (2008) have reported that health care providers will provide more information to women on cervical cancer and the benefits of taking part in cervical cancer screening programs. [45]

The results of the present study revealed that the mean scores of women' knowledge before the program implementation was deficient about the treatment of cancer but there was a significant improvement immediately post-program and after three months of program implementation. Knowledge before the program implementation controversy with Salaudeenet al., (2009) who study awareness and attitudes towards cancer and among female graduates in Nigeria showed that approximately two-thirds $(65.4 \%)$ of respondents had good knowledge of cancer treatment options. Surgery, chemotherapy, and radiotherapy were the treatment options that respondents identified. [46]

It was evident from the results of the present study that, more than half of the studied women had a negative attitude about cervical cancer and early detection measures before program implementation. This negative attitude may be attributed to the horrible feeling of each participant toward such disease of unknown cause and poor prognosis. This result was contraindicated by Korfage et al., (2011) who found that the attitude towards cervical screening was overwhelmingly positive $(99 \%)$ and, also, reported that; the key reasons for attendance were early detection of abnormalities (67\%) and reassurance in case of a normal smear (22\%). [47]

Additionally, Chukmaitov et al., (2008) who examined cancer awareness and attitudes toward screening as predictors of cancer preventive behavior in Kazakh, Korean, and Russian women in Kazakhstan, stated that attitudes to the effectiveness of screening are significant determinants of cancer preventive practices among 
participants in the study. [48] Also, Dang et al., (2010) stated that the majority of the study subject seemed to have positive attitudes regarding cancer and health behavior. [18]

However, after program implementation findings the highly statistically significant difference related to the readiness of the participants $(\mathrm{p}<0.001)$. This result could be due to the effectiveness of the program. This finding in congruence with Gürsoy et al., (2009) who emphasized that; the educational program provided the participant with valuable information that can influence health beliefs related to cancer. [49] Moreover Yang et al., (2010) stated that the selected group of women who attended the cancer program might have already had a positive attitude towards screening. [50]

In addition, Al-Naggar et al (2010) reported that while information about the screening of cervical cancer is sufficient, they have a very poor practice of Pap smear testing in some cases. [51] A small percentage of doctors referred their patients for regular screening as shown by Al-Naggar et al., (2010). The principal reason given was the procedure's high expense. [52] Moreover, Anhang et al., (2010) indicated that optimum screening results can be achieved when health care organizations customize cancer screening approaches and interfaces that are most important for their organizations, their clinicians and the patients they serve. [53] In addition, Nuño et al., (2010) recorded that, relative to the normal treatment group, women in the intervention group were 1.5 times more likely to report receiving a smear in the last year. [26]

There is a need to increase awareness among working women about their role in the fight against cervical cancer through focused education and training programs. Azaiza et al., also recorded that the participants identified a combination of intimate, cultural and environmental barriers to be overcome through educational programs, accompanied by early detection and treatment services for cervical cancer. [54] In addition Ballew et al., (2010) reported that the most common reasons for not being screened were the conviction of the respondent that it was not necessary, added that the subjects of the study remain unaware of the value of screening for cancer. The author concluded that women's awareness must be improved by health care professionals and public health authorities, and professionals have to continue to refer patients for screening. [55]

As regards barriers or reasons for not practicing Pap smear test before the program, more than one-third of the studied women in the present study were lack of knowledge about the importance Pap smear test. Additionally, the scope of cancer screening services in Egypt and the lack of screening in Egyptian culture are still minimal. This result was supported by Amin, (2012) stated that Arabic speaking immigrant women did not have Pap test because of a lack of understanding about its importance or the lack of recommendation by a physician to have such tests done. [56] Also, Abdullahi et al., (2009) who researched cervical screening: perceptions and obstacles for Somali women in Camden reported that language difficulties and unique cultural issues are key obstacles to first-generation Somali women attending cervical screening and recommended that, providing oral information and education, as well as increase access to a more culturally appropriate screening service, could lead to better integration among this group. [57]

Al-Naggar et al (2010), on the other hand, reported that while awareness of cervical cancer screening is sufficient, they have a very poor practice of Pap smear testing. The most common barriers in the screening of cervical cancer were the smear test that would make them worry (95.8\%). [51] Also Nwankwo et al., (2010), also, found out that the most significant factors hindering the use of available cervical cancer screening services were the impression that they were no medical issues.

It was evident from the results of the present study that, more than half of the studied women had a negative attitude about cervical cancer and early detection measures before program implementation. This negative attitude may be attributed to the horrible feeling of each participant toward such disease of unknown cause and poor prognosis. This result was contraindicated by Korfage et al., (2011) who found that the attitude towards cervical screening was predominantly positive and reported also the key reasons for attendance were early identification of abnormalities \& reassurance in case of a normal smear. [47]

The findings of this study showed that there was a positive significant correlation at various test periods between total knowledge and total attitude scores as well as total knowledge and total practice scores. The results are consistent with $\mathrm{Abd} \mathrm{El} \mathrm{Aziz} \mathrm{et} \mathrm{al.,} \mathrm{(2009),} \mathrm{who} \mathrm{examined} \mathrm{the} \mathrm{effect} \mathrm{of} \mathrm{a} \mathrm{health} \mathrm{education} \mathrm{intervention} \mathrm{program} \mathrm{on}$ cervical cancer among women in Alexandria's semi-urban region, commented that women's awareness score was significantly correlated with screening practice. [32]

\section{Conclusion}

In light of the study findings, the implementation of an educational program led to significant improvements in women's knowledge, attitude, and practice. After the educational program was introduced, women's awareness, 
attitude and practice about cervical cancer were strengthened. The existence of a strong connection has been established in the research between their awareness and attitude and practice. That means; hypothesizes of the research are accepted.

\section{Recommendations}

1. More rigorous researches are required to explore the long-term impact of these programs and to plan an individualized educational system in formulating their educational program.

2. There is a strong need for replicating the research on wider samples in various settings and developing health education initiatives for women with regard to the most common cancer among women, to raise awareness, reinforce beliefs and attitudes. Early detection of cervical cancer is also of great importance for improving women's health and reducing the risk of death from cancer.

\section{References}

[1] Pinar, G., Pinar, T., \& Akalin, A. (2015). Problematic Areas Related to Sexual Life of Individuals with Gynecological Cancer: A qualitative Study in Turkey. International Journal of Hematology and Oncology, 25(3), 195-204. https://doi.org/10.4999/ uhod.151090

[2] Hassan, H., \& Atwa, A. (2017). Occupational Stress, Job Satisfaction and Cervical Screening. Intention of Maternity Oncology Nurses, Medical Science \& Healthcare Practice, 1(1), 48-59. https://doi.org/10.22158/mshp.v1n1p48

[3] Hassan, H., Bayoumi, M., \& Atwa, A. (2016). Emotional Distress Associated with Gynecologic and Breast Cancer in Beni-Suef City. International Journal of Science and Research, 5(2), 1118-1129

[4] Atwa, A., Hassan, H., \& Ahmed, S. (2019). The impact of a hospital-based awareness program on the knowledge of patients about breast cancer and cancer cervix. International Journal of Studies in Nursing, 4(1), 20-29. https://doi.org/10.20849/ijsn.v4i1.537

[5] Underwood, S. M., Ramsay-Johnson, E., Dean, A., Russ, J., \& Ivalis, R. (2009). Expanding the Scope of Nursing Research in Low Resource and Middle Resource Countries, Regions, and States Focused on Cervical Cancer Prevention, Early Detection, and Control. Journal of National Black Nurses Association, 20(2), $42-54$.

[6] Said, S., Hassan, H., \& Sarhan, A. (2018). Effect of an Educational Intervention on Women's Knowledge and Attitude Regarding Cervical Cancer. American Journal of Nursing Research, 6(2), 59-66. https://doi.org/10.12691/ajnr-6-2-4

[7] Cancer Net Editorial Board (CNEB). (2016). Ovarian, Fallopian Tube, and Peritoneal Cancer. Introduction.

[8] Cancer Research United Kingdom. (2016). Let's beat cancer sooner, Fallopian tube cancer.

[9] Hussein, I., Khaled, M., NH Mikhail, N., Baraka, H., \& Kamel, H. (2014). Cancer Incidence in Egypt: Results of the National Population-Based Cancer Registry Program. Journal of Cancer Epidemiology, 18.

[10] Mohammed, F., Shahin, M., Youness, E., \& Hassan, H. (2018). Survivorship in Women Undergoing Gynecological and Breast Cancer Treatment in Upper Egypt: The Impact of Quality of Life Improvement Educational Program. American Research Journal of Gynaecology, 2(1), 1-28. doi:10.21694/2577-5928.18001

[11] Abdul-Aziz, M. (2012). Knowledge, Attitude and Practice towards Cervical Cancer among Reproductive Health Clients at the University of Science \& Technology Hospital-Sana'a in Yemen. Yemeni Journal for Medical Sciences, (6).

[12] Qalawa, Sh., Eldeeb, A., \& Hassan, H. (2015). Young Adult Women's intention regarding breast and cervical cancer screening in Beni-Suef. Scientific Research Journal, 3(3), 11-24.

[13] Ali, S. F., Ayub, S., Manzoor, N. F., Azim, S., Afif, M., Akhtar, N., ... Uddin, N. (2010). Knowledge and Awareness about Cervical Cancer and its Prevention amongst Interns and Nursing Staff in Tertiary Care Hospitals in Karachi, Pakistan. Public Library of Science one, 5(6), E11059.

[14] Nady, F., El-Sherbiny, M., Youness, E., \& Hassan, H. (2018). Effectiveness of Quality of Life Planned Teaching Program on Women Undergoing Gynecologic Cancer Treatment. American Research Journal of Oncology, 1(1), 1-17.

[15] Anorlu, R. I. (2008). Cervical Cancer: the Sub-Saharan African Perspective. Reproductive Health Matters, 
$16(32), 41-49$.

[16] Almonte, M., Albero, G., Molano, M., Carcamo, C., García, P. J., \& Pérez, G. (2008). Risk Factors for Human Papillomavirus Exposure and Co-Factors for Cervical Cancer in Latin America and the Caribbean. Vaccine, 26(11), 16-36.

[17] Mcfarlane-Anderson, N., Bazuaye, P. E., Jackson, M. D., Smikle, M., \& Fletcher, H. M. (2008). Cervical Dysplasia and Cancer and the Use of Hormonal Contraceptives in Jamaican Women. BMC Women's Health, 8(9). Retrieved from http://www.biomedcentral.com/1472-6874/8/9

[18] Dang, J., Lee, J., \& Tranjh. (2010). Knowledge, Attitudes, and Beliefs Regarding Breast and Cervical Cancer Screening among Cambodian, Laotian, Thai, and Tongan Women. Journal of Cancer Education, 25(4), 595-601.

[19] Nady, F., Said, M., Youness, E., \& Hassan, H. (2018). Effect of Nursing Intervention Program on Quality of Life Improvement for Women Undergoing Gynecological and Breast Cancer Treatment. Assuit Scientific Nursing Journal, 6(15), 62-77.

[20] Rogers, N. M., \& Cantu, A. G. (2009). The Nurse's Role in the Prevention of Cervical Cancer among Underserved and Minority Populations. Journal of Community Health, 34(2), 135-143.

[21] Mohamed, A., Hassan, H., Gamel, W., \& Arafa, A. (2019). Awareness about breast and cervical cancers among nursing students in Beni-Suef University. Journal of Nursing Education and Practice, 9(5), 44-51. https://doi.org/10.5430/jnep.v9n5p44

[22] Salem, A. S., Salem, M. A., \& Abbass, H. (2010). Breast Cancer: Surgery at the South Egypt Cancer Institute. Cancers Journal, 2(1), 1771-1778.

[23] WHO. (2011). Breast Cancer: Prevention and Control. Retrieved from http:/Www.Who.Int/Cancer/Detection/Breastcancer/En/Index3.Html

[24] Othman, A., Ahram, M., Al-Tarawneh, R., \& Shahrouri, M. (2015). Knowledge, Attitudes and Practices of Breast Cancer Screening Among Women in Jordan. Health Care Women Int., 36(5), 578-592. https://doi.org/10.1080/07399332.2014.926900

[25] El-Zanaty and Associates. (2015). Egypt Health Issues Survey 2015. Cairo, Egypt: Ministry of Health and Population/Egypt and ICF International. Retrieved March 26, 2018, from https://dhsprogram.com/pubs/pdf/FR313/FR313.pdf

[26] Nuño, O., Erinosho, L., Jamda, M., Olaniyi, O., Adelaiye, R., Lawson, L., ... Zamani, A. (2010). Knowledge and Attitudes towards Cervical Cancer and Human Papillomavirus: a Nigerian Pilot Study. African Journal of Reproductive Health, 14(1), 95-108.

[27] Arshad, S., Williams, K. P., Mabiso, A., Dey, S., \& Soliman, A. S. (2010). Evaluating the Knowledge of Breast Cancer Screening and Prevention among Arab-American Women in Michigan. Journal of Cancer Education, 26(1), 135-8.

[28] Hajian-Tilaki, K. O., \& Kaveh-Ahangar, T. (2010). Reproductive Factors Associated with Breast Cancer Risk in Northern Iran. Medical Oncology.

[29] Torres-Mejía, G., \& Angeles-Llerenas, A. (2009). Reproductive Factors and Breast Cancer: Principal Findings in Latin America and the World. Public Health Mexico, 51(2), 165-171.

[30] Taha, H., Halabi, Y., Berggren, V., Jaouni, S., Nyström, L, Al-Qutob, R., \& Wahlström, R. (2010). Educational Intervention to Improve Breast Health Knowledge among Women in Jordan. Journal of Cancer Prevention, 11(5), 1167-1173.

[31] Rao, S. P., Nair, S., Nair, N. S., \& Kamath, V. G. (2013). Acceptability and Effectiveness of A Breast Health Awareness Programme for Rural Women in India. Indian Journal of Medical Science, 59(9), 398-402.

[32] Abd El Aziz, H. M., Akl, O. A., \& Ibrahim, H. K. (2009). Impact of a Health Education Intervention Program about Breast Cancer among Women in a Semi-Urban Area in Alexandria, Egypt. Journal of Egypt Public Health Association, 84(1), 2-19.

[33] Karayurt, O., Özmen, D., \& Çetinkaya, A. C. (2008). Awareness of breast cancer risk factors and practice of breast self examination among high school students in Turkey. Biomedcentral, Public Health, 8(359). Retrieved from http:/www.Biomedcentral.Com/1471-2458/8/359

[34] Banning, M. (2010). Perceptions of Breast Health Awareness in Black British Women. Eurpean Journal of 
Oncology Nursing.

[35] Gupta, S. K. (2009). Impact of a Health Education Intervention Program Regarding Breast Self Examination by Women in A Semi-Urban Area of Madhya Pradesh, India. Journal of Cancer Prevention, 10(6), 1113-1117.

[36] Wright, K. O., Kuyinu, Y. A., \& Faduyile, F. A. (2010). Community Education on Cervical Cancer amongst Market Women in an Urban Area of Lagos. Nigeria. Asian Journal of Cancer Prevention, 11(1), 137-140.

[37] Al Sairafia, M., \& Mohamed, F. A. (2009). Knowledge, Attitudes, and Practice Related to Cervical Cancer Screening among Kuwaiti Women, Medical Principles and Practice. International Journal of the Kuwait University, 18(1), 35-42.

[38] Hoque, M. E. (2010). Cervical Cancer Awareness and Preventive Behaviour among Female University Students in South Africa. Asian Journal of Cancer Prevention, 11(1), 127-130.

[39] Head, S. K., Crosby, R. A., \& Moore, G. R. (2009). Pap smear Knowledge among Young Women Following the Introduction of the HPV Vaccine. Journal Pediatric Adolescent Gynecology, 22(4), 251-256.

[40] Tan, Y. Y., Hesham, R., \& Qodriyah, H. M. (2010). Knowledge and Attitude of University Students in Health Sciences on the Prevention of Cervical Cancer. Medical Journal of Malaysia, 65(1), 53-57.

[41] Ilter, E., Celik, A., Haliloglu, B., Unlugedik, E., Midi, A., Gunduz, T., \& Ozekici, U. (2010). Women's Knowledge of Pap Smear Test and Human Papillomavirus: Acceptance of HPV Vaccination to Themselves and their Daughters in an Islamic Society. International Journal of Gynecological Cancer, 20(6), 1058-1062.

[42] Peters, L. M., Soliman, A. S., Bukori, P., Mkuchu, J., \& Ngoma, T. (2010). Evidence for the Need of Educational Programs for Cervical Screening in Rural Tanzania. Journal of Cancer Education, 25(2), 153-159.

[43] O'Brien, M. J., Halbert, C. H., Bixby, R., Pimentel, S., \& Shea, J. A. (2010). Community Health Worker intervention to Decrease Cervical Cancer Disparities in Hispanic Women. Journal of International Medicine, 25(11), 1186-1192.

[44] Papa, D., Moore Simas, T. A., Reynolds, M., \& Melnitsky, H. (2009). Assessing the Role of Education in Women's Knowledge and Acceptance of Adjunct High-Risk Human Papillomavirus Testing For Cervical Cancer Screening. Journal of Lower Genital Tract Disease, 13(2), 66-71.

[45] Allahverdipour, H., \& Emami, A. (2008). Perceptions of Cervical Cancer Threat, Benefits, and Barriers of Papanicolaou Smear Screening Programs for Women in Iran. Women Health, 47(3), 23-37.

[46] Salaudeen, A. G., Akande, T. M., \& Musa, O. L. (2009). Knowledge and Attitudes to Breast Cancer and Breast Self-Examination among Female Under Graduates in a State in Nigeria. European Journal of Social Sciences, 7(3), 157-165.

[47] Korfage, I. J., Van Ballegooijen, M., Wauben, B., Habbema, J. D., \& Essink-Bot, M. L. (2011). Informed choice on pap smear still limited by lack of knowledge on the meaning of false-positive or false-negative test results. Patient Education Counsel.

[48] Chukmaitov, A., Wan, T. H., Menachemi, N., \& Cashin, C. (2013). Breast Cancer Knowledge and Attitudes Toward Mammography as Predictors of Breast Cancer Preventive Behavior in Kazakh, Korean, and Russian Women in Kazakhstan. International Journal of Public Health, 53(3), 123-130.

[49] Gürsoy, A. A., Hindistan, S., Nural, N., Kahriman, I., Yilmaz, F., Yigitbas, C., ... Mumcu, H. K. (2009). Comparison of Three Educational Interventions on Breast Self-Examination Knowledge and Health Beliefs. Asian Pacific Journal of Cancer Prevention, 10(5), 765-772.

[50] Yang, R. J., Huang, L. H., Hsieh, Y. S., Chung, U. L., Huang, C. S., \& Bih, H. D. (2010). Motivations and Reasons for Women Attending a Breast Self-Examination Training Program: a Qualitative Study. Womens Health, 10(1), 23.

[51] Al-Naggar, R. A., Low, W. Y., \& Isa, Z. M. (2010). Knowledge and Barriers towards Cervical Cancer Screening among Young Women in Malaysia. Asian Journal of Cancer Prevention, 11(4), 867-873.

[52] Al-Naggar, R. A., Isa, Z. M., Shah, S. A., Chen, R., \& Kadir, S. Y. (2010). Mammography Screening: Female Doctors' Attitudes and Practice in Sana'a, Yemen. Asian Journal of Cancer Prevention, 10(5), 743-746. 
[53] Anhang Price, R., Zapka, J., Edwards, H., \& Taplin, S. H. (2010). Organizational Factors and the Cancer Screening. Journal of the National Cancer Institute, (40), 38-57.

[54] Azaiza, F., Cohen, M., Awad, M., \& Daoud, F. (2010). Factors Associated with Low Screening for Breast Cancer in the Palestinian Authority: Relations of Availability, Environmental Barriers, and Cancer-Related Fatalism. Journal of Cancer, 116(19), 4646-4655.

[55] Ballew, C., Cummings, S. J., \& Oreskovich, J. (2010). Reported Barriers to Cancer Screening: Montana Behavioral Risk Factor Surveillance System 2007. American Journal of Health Promotion, 24(5), 311-314.

[56] Amin, M. A. (2012). Knowledge, Beliefs, Attitudes and Perceptions About Breast and Cervical Cancer and Screening among Arabic Speaking Immigrant Women in Halifax, Nova Scotia. Master Thesis, the Faculty of Education, Mount Saint Vincent University.

[57] Abdullahi, A., Copping, J., Kessel, A., Luck, M., \& Bonell, C. (2009). Cervical Screening: Perceptions and Barriers to Uptake among Somali Women in Camden. Public Health, 123(10), 680-685.

\section{Copyrights}

Copyright for this article is retained by the author(s), with first publication rights granted to the journal.

This is an open-access article distributed under the terms and conditions of the Creative Commons Attribution license (http://creativecommons.org/licenses/by/4.0/). 